\section{Thromboembolism: Diagnosis and Treatment}

Edited by V. V. Kakmar and A. J. Jouhar. Proceedings of a Symposium held at King's College Hospital, London. Edinburgh: Churchill Livingstone, 1972. $£ 3.50$.

This small volume provides a useful summary of the many recent advances in diagnosis and management of venous thrombosis and pulmonary embolism. The newer tests for diagnosing deep vein thrombosis, in particular improved techniques of venography and the radioactive fibrinogen test, are seen to provide that precision in diagnosis without which causative factors cannot be identified and prophylactic and therapeutic measures cannot be evaluated.

Turning to medical treatment, it is perhaps to be expected that opinions will differ on the value of such recently introduced drugs as the thrombolytic agents. It is unfortunate, however, that major differences in dosage schedule for streptokinase, in the recommended laboratory monitoring procedures, and above all in the clinical indications for the therapy, are allowed to pass with so little comment. For example, in the treatment of pulmonary embolism, thrombolytic therapy is variously described as "likely to become the treatment of first choice' and as 'likely to have a very limited place'.

Despite this criticism, however, this is a book which will be particularly appreciated by all those practising clinicians who have not managed to remain abreast of the literature in this most important field.

\section{Atlas of Haematology}

By G. A. McDonald, T. C. Dodds and B. Cruickshank. Foreword by Sir Stanley Davidson. Pp. 226, illustrated. Edinburgh and London: E. \& S. Livingstone, 1970. £5.50. This beautifully produced atlas is now in its third edition only 6 years after its first publication. On looking through the present edition it is easy to see why it has been such an outstanding success.

After a preliminary description of the development of the blood cells successive sections deal with the appearances of the normal peripheral blood film and bone marrow preparations. A very full description of most of the common abnormalities of red cells and their precursors follows and succeeding sections deal with the white cells and platelets in a similar fashion. Interspersed with these sections are excellent photomicrographs of the liver and spleen in various haematological disorders, phase contrast microscopic studies of a selected group of red cell and white cell abnormalities and a short but beautifully illustrated section on the stereoscan electron-microscopic appearances of normal and abnormal blood cells. There are further sections on tumours of lymphoid tissue and the book closes with a gentle reminder about commonly seen artefacts.

The book is most beautifully produced and the photographs are uniformly excellent. Although the arrangement of material appears at first glance to be somewhat haphazard, half the charm of this atlas is that one is never quite sure what is going to turn up on the next page and an adequate index serves as a guide for rapid reference.

No haematology laboratory or department involved in haematological research can afford to be without this excellent book which will be as useful for undergraduates as it is for postgraduates and as a continued source of reference for specialists.

It is extremely sad that one of the authors, Mr T. C. Dodds, did not survive to see the appearance of this third edition The book is a fitting memorial to his superb skill as a medical photographer and it is doubtful whether any future atlas will equal its standard in terms of photographic work. 